\title{
POÉTICA Y COMUNICACIÓN \\ Aportaciones a la teoría de la comunicación y a la teoría de los objetos desde las Odas de Neruda
}

\author{
POETRY AND COMMUNICATION \\ Contribution to the communication theory and to the object theory from \\ Neruda's Odes
}

\author{
OctaVIo UÑa octavio.una@urjc.es \\ Universidad Rey Juan Carlos. España.
}

\begin{abstract}
RESUMEN
Quiere situarse el presente estudio en una línea de investigación sobre lenguajes elaborados y teoría de la comunicación, en la que se incluyen estudios sobre la obra poética de Octavio Paz y sobre el pensamiento de Gadamer en torno al lenguaje y a la obra de arte. Establecemos aquí un primer acceso a las Odas elementales de Neruda desde la perspectiva fenomenológica de los objetos, la consideración del lenguaje poético y sus aportaciones a la comunicación ("la poesía es la comunicación, establecida con nuevas palabras, de un conocimiento de muy especial índole", sostiene Bousoño). Objetos que miran y convergen hacia el hombre, objetos de la vida cotidiana, de los entornos cercanos y cálidos: una construcción del reino de la objetividad, "surtidor de metáforas". Todo un inventario poético del mundo de lo "a la mano", de la proxémica; un relato y crónica de la experiencia del poeta, dialógica, y del acervo de la experiencia común. Objetos polisémicos, que expresan, informan y dicen "sistemas estructurados de signos".
\end{abstract}

\section{Palabras Clave}

Lenguaje y comunicación; Lenguaje poético; Neruda; Objetos; Odas elementales; Poética y fenomenología.

\begin{abstract}
The present study is classified within a research line related to elaborated kinds of languages and to the communication theory, in which two types of studies are included, those studies about the poetic work by Octavio Paz and those studies about Gadamer's thoughts on language and the work of art. We establish a first approach to Neruda's Elemental Odes form the phenomenological perspective of the objects, the consideration of poetic language and its contributions to communication (Bousoño maintains that "poetry is the type of communication, established by using new words, of a very special kind of knowledge"). Objects that look at and converge toward men, everyday life objects, objects from warm and nearby environments: the construction of objectivity kingdom, "metaphor provider". A whole poetic inventory from the "at hand" world, from proxemics, an account and a chronicle of the poet's experience, which is dialogic, and of the heritage of the common experience. Polisemic objects, which express, inform and say "structured sygn systems".
\end{abstract}

\section{KEYWORDS}

Elemental Odes; Lenguage and Communication; Neruda; Poetics and Phenomenology; Poetic Language; Objects. 


\section{Algunos antecedentes teóricos}

En su célebre conferencia de 1950 sostenía Heidegger que la lengua es morada del hombre: ella nos llama, nos acerca a las cosas y nos invita a ir a ellas, articulando de originalísimo modo la diferencia entre lo particular y lo universal ${ }^{1}$. Traducía así el filósofo el sentir de Hölderlin: "Habita el hombre poéticamente". Para Rilke, por otra parte, los poetas amplían las capacidades lingüísticas y Gadamer concluye que la palabra "se consuma en la palabra poética" (1998: 48). Teóricos de los lenguajes elaborados, especialmente desde las aportaciones de Barthes, argumentan que la literatura viene a ser "un fenómeno de comunicación verbal en que la palabra se sustantiva por su carácter simbólico" (Morón Arroyo 1998: 53). La palabra poética, antes que realidad, dice comunicación. Aquella triple naturaleza de los signos - expresar, significar, comunicar-se cumple en el lenguaje, también en los lenguajes altamente elaborados y especialmente en el lenguaje poético. Ya B. Arias Montano, conocedor de los secretos de los signos y símbolos y ciudadano de universos plurilingües, formulaba esta original propuesta: "Poseyeran [los hombres] asimismo algún arte, mediante el cual la comunicación de noticias fuera abierta y la explicación de los afectos resultara mejor y más certera" (2009: 112). Lo que I. M. Zavala concreta taxativamente: "El 'yo' solo existe relacionado a un 'tú'... la construcción del yo mediante lo verbal pasa por el diálogo como forma primaria de comunicación y pensamiento y, más aún, como concepción del sujeto y su ser" (2009: 24-25). Es más, la palabra poética conjura la realidad para que se patentice y exprese como es para nosotros. Los "hechos de la cultura", a diferencia de los hechos físicos y biológicos, remiten a "algo más", como describe Barthes (2002: 25).

La dialéctica sujeto-objeto y la dialéctica objeto-sujeto están en la base de una amplísima reflexión que va desde Aristóteles a Descartes y Kant y toma su último desmedido cuerpo en la fenomenología. La definición de sujeto y objeto, la relación intencional y dialéctica entre un sujeto y un objeto, como quiere definir el conocimiento N. Hartmann, la relación entre "mi mundo" y "el mundo general", la constitución del mundo en la conciencia, la mismidad y la alteridad, forman parte de una reflexión central y decisiva para la historia del pensamiento. El poeta templa aquí sus armas: aquella titánica e interminable desobjetivación-reobjetivación, por obra y gracia de la palabra creadora. La teoría del conocimiento y la epistemología vieron al objeto como aquello sobre lo cual cae algún poder o condición, perfilaron los conceptos de objeto material, objeto formal, objeto real, objeto extramental, objeto ideal, "cosa en si", objeto trascendental,

\footnotetext{
${ }^{1}$ Este artículo forma parte de la participación del autor en el proyecto de investigación "América en España. Los lazos comunes" (Referencia G81998007), financiado por el Ministerio de Cultura. Las referencias a los estudios de Octavio Paz (Uña 2007) y al planteamiento de Gadamer sobre el lenguaje y la obra de arte (Uña 2008) deben entenderse dentro de las líneas de investigación del seminario "Theodor W. Adorno" del departamento de Ciencias Sociales de la Universidad Rey Juan Carlos, del cual es fundador y director el autor.
} 
objeto conocido, fenómeno, noúmeno, "contenido intencional", "objeto de conocimiento", objetos físicos, objetos intencionales, objetos significativos... El discurso filosófico venía a desentrañar el objeto desde el universo ontológico, el epistemológico y el del lenguaje. También desde la teoría de los objetos. La filosofía labró otros perfilamientos de los objetos: mundo sensible, mundo inteligible, ser finito, ser infinito, sustancia extensa, cuerpo y alma, naturaleza e historia, cuerpo, alma y espíritu... Muy diversas tipologías van a tratar de enmarcar este plural reino: objetos reales, objetos ideales, objetos-valor, objetos metafísicos (A. Müller); objetos ideales, objetos individuales, objetos determinados por la temporalidad, objetos intencionales (R. Ingarden); objetos de los sentidos, objetos perceptuales, objetos científicos (A. N. Whitehead); objetos conceptuales, objetos trascendentales, objetos ideales, entidades reales, esencias (H. Conrad-Martius); objetos concretos, objetos fenoménicos, objetos generales, hechos objetivos (M. Honecker). En otro orden de cosas, W. Sombart (1979: 64) abundaba sobre los "objetos de lujo". J. Baudrillard daba luz sobre el sistema de los objetos: funcional, disfuncional, marginal, socioideológico (1977). Moles, por su parte, discurría sobre la resistencia del sujeto al objeto, sobre el carácter material del objeto, sobre su permanencia e inercia, incidiendo también en la artificialidad del objeto, en la complejidad estructural y funcional del sistema de los objetos, así como en los objetos como mensaje (1975b). S. Zizek concluía: "Es el nombre, el significante, el que soporta la identidad del objeto" (2010). Objetos como realidades de la naturaleza, objetos como hechos y quehaceres del hombre, objetos como útiles, objetos como entidades, objetos como personas, objetos como conductas aparecen en la vibrante palabra de Neruda, que rompe toda estructura, toda forma dada y, ligerísimos de equipaje, se acumulan, se identifican, se suceden, dicen, gritan, cantan, señalan, alumbran y afirman, pueblan de claridad los espacios, saludan, porfían e increpan. Va en ellos el sujeto, ellos son sujetos. Ellos son el mundo, el conjunto de lo significante.

Como Barthes estableció, revisando presupuestos de la semántica, los objetos habitan en la profundidad metafórica, son polisémicos y también cumplen determinadas funciones. "Significar quiere decir que los objetos no transmiten solamente informaciones, sino también sistemas estructurados de signos, es decir, esencialmente sistemas de diferencias, oposiciones y contrastes" (2003: 248). Así en Neruda los objetos son un magma, cúmulo y legión de realidades, una constelación abigarrada de significación, de invocación y de cuestionamiento para el hombre. Neruda esgrime sus múltiples recursos hasta hacer hablar a la variedad del mundo: su naturaleza, sus estructuras, sus funciones, sus perfiles, su singularidad en el entramado de la totalidad, traduciendo a visible y transparente lo recóndito e invisible del mundo. La instantaneidad, la evanescencia, la perduración, la consistencia, la diafanidad, la lúdica, la originaria instancia de las cosas encuentran aquí su mano creadora y mágica. Entra el poeta en un taller de grave trabajo y acumulado sufrimiento: la relación sujeto-objeto. Safranski piensa que filosofía y poesía trabajan en la "rehabilitación del mundo fenoménico" (2006: 53). El creador chileno hace aquí un alarde también de fenomenología desde sus construcciones metafóricas. 
Por su parte, el extraordinario hermeneuta Amado Alonso, ensalzando la fantasía emocionada del poeta, propone como piedra clave metodológica para el análisis del discurso del vate chileno "la objetivación de lo subjetivo y la subjetivación de lo objetivo" (1997: 45).

\section{En el taller nerudiano. Propósitos y objetivos}

Acotamos aquí nuestras reflexiones al Neruda de Odas elementales (1954), Nuevas odas elementales (1956), Tercer libro de odas (1957) y Navegaciones y regresos (1959). A la sombra de Horacio y Góngora (Brunori 1930; Brink 1963; Suárez de la Torre 2007; Horacio 2008), el gran poeta hace suya la diversidad, el tupido conjunto de la diferencia, la amplitud de lo real, el reino de la experiencia común, desde el lenguaje precisivo, contenido, singularizador y definitorio. La innumerable familia de los objetos, desde los Andes a un par de tijeras, a la madera o al ajo, son aquí, límpidos y barrocos, vestidos e investidos, descritos y transfigurados a merced de geniales invenciones y proyecciones del poeta chileno. Así los milagros expresivos y comunicativos de esta "poesía herramienta, utilitaria ferretería", como ha sido calificada. "En Neruda, la oda tiene la universal ductilidad de ilustrar cualquier objeto, acto, cualidad" (Yurkievich 2005: 74).

Pere Gimferrer, abundando sobre la palabra poética, venía a concluir: "El poema es, entonces, un objeto ambiguo: impersonal y personalísimo, al mismo tiempo, cotidiano e insólito, autónomo de sentido y cargado de pensamiento latente en su tejido mismo. Esta fascinante condición enigmática es la que siempre, de manera bipolar, ha seducido a los poetas mismos, divididos entre la pura atracción de las palabras y la capacidad que las palabras tienen para suscitar pensamiento. Pero este pensamiento no nace necesariamente de conceptos, sino que puede nacer de las imágenes... nace... del ritmo y del sonido..." (2009: 61). Ello es aplicable al gran creador que es Neruda, quien imparte en estos poemarios un excelente y original discurso sobre los objetos: unos objetos de la cotidianidad y de los ámbitos de la cercanía en la que la vida humana se realiza y resuelve. Conceptos, términos, imágenes, ritmos, que van a desentrañar y a edificar, en una "construcción" fenomenológica, el reino de la objetividad, la población de lo "a la mano". La agudeza de Gracián definió el concepto como "un acto del entendimiento que exprime la correspondencia que se halla entre los objetos" (1987: 55). Y máxima es la agudeza, máximas las artes de ingenio nerudianos al intuir y expresar hermosamente mil notas, mil perfiles, mil características de ese mundo "lleno de dioses", que quería el poeta griego, del prado florido de la realidad que pintaba arcangélicamente Berceo. El "complicado arte del poeta chileno Pablo Neruda" (Del Río 2010: 394) lleva a cabo esta amplia faena de hacer hablar al universo mundo poniendo ordenamientos sígnicos, cosmos, "pulcherrimum carmen" en lenguaje agustiniano, sobre la nuda y cruda realidad, impenetrable, hermética, también torva y siniestra en lenguaje sartriano. Hasta hacer de la variada corte de los objetos llamada a las palabras, levantando el mundo por 
obra y gracia del lenguaje a aquel estado originario y puro que proponía W. Benjamin, frente al "estado de caído", venido a menos (1986: 318). Las cosas todas, el "pío general de las criaturas", intensas, acentuadamente significantes, objectas, es decir, lanzadas como flechas a la mirada y ánimo del sujeto, incitantes e invocadoras de sus capacidades perceptivas y discursivas: así va el mundo hacia las observaciones y atenciones del poeta. "El poeta, decía Huidobro (1996: 96), reconoce el eco de los llamados de las cosas a las palabras, ve los lazos sutiles que se tienden las cosas entre sí, oye las voces secretas que se lanzan unas a otras palabras separadas por distancias inconmensurables". Pablo Neruda impele, ordena, obliga a las palabras al anuncio y pronunciamiento de la realidad con total precisión, con señalización y advertencia de aspectos, notas, formas, propiedades y señales mil del mundo ancho y alegre. Pensaba Lacan que el poeta, como por juego, se tornaba en surtidor de metáforas. Las asociaciones semánticas, las comparaciones, las traslaciones (sobre todo, las "usurpadas" traslaciones que dan cuerpo a las metáforas), las anáforas y otros variados procedimientos habitan acumulada y genialmente en el taller del chileno.

"El Neruda de las Odas elementales también podría haber suministrado muchos ejemplos y tipos de agudeza... Los poemas están compuestos a menudo a partir de un concepto inicial que siente las bases de las analogías posibles... Así sucede, por ejemplo, con la cebolla, "luminosa redoma", "clara como un planeta", o con el espléndido octosilabo "redonda rosa de agua", donde comparecen los tres rasgos esenciales que vertebran el poema, los dos presentes en las citas anteriores (redondez y claridad) y la forma por capas (como una flor rústica). Otro caso de agudeza puede ser "Oda a la alcachofa": el concepto inicial ("La alcachofa / de tierno corazón / se vistió de guerrero") fructifica en otros conceptos afines y nos da la pauta del entero poema (el contraste entre la dulce suavidad del interior y el aparatoso blindaje): "y comemos / la pacífica pasta / de su corazón verde" (Micó 2008: 179).

Neruda quería que sus versos fueran "un relámpago de fulgor persistente" (él que veía a Lorca como "un negro relámpago perpetuamente libre"). Se quiere como clamor, cántico, cenital claridad, permanente alborada y maremágnum. Se quiere perpetuado en el instante luciente, intenso y profundo. Y aquí se cumple su deseo: en las Odas el autor transita de la "expresión de una supuesta subjetividad..." a "la fulguración de una masa de lenguaje en movimiento". Tránsito excelentemente descrito por I. M. Zavala (2009: 53). Neruda magmático, cosmogónico, telúrico, olímpico, atlante, exuberante; pero a su vez ajustado, metodológico, fiel a una estructura fijada, a una progresión-reiteración en la plasmación de sus odas. Jorge Edwards habla del racionalismo de las Odas elementales (2010: 14) como aquel secreto hilo conductor del De figura cubica Tractatus de Juan de Herrera para medir, pesar y contar la inmensa edificación escurialense. Así, el poeta pesa, mide, ordena, compara, remite, relaciona, cuenta los amplios recintos, el ancho mundo, orbes y constelaciones, el gran libro de la naturaleza, el amplísimo reino de la diferencia, el texto de la plurimorfa y polísona realidad, que invoca, pide, 
exige un atento y sensibilísimo lector (graves cuestiones de Schopenhauer y Scheler entre mundo y sujeto, entre sujeto y mundo, o la invocación del mundo como lenguaje, al modo de Arias Montano en De arcano sermone, o como abierto cantoral de la significación para un lector, al modo de U. Eco). Barthes (2001: 176) abunda en la relación directa e imprescindible de la literatura con los "valores situados" y Safranski (2009: 22) ve a Herder superar la relación con Kant invocando una "razón viva concreta" sumergida en la "vida oscura, creadora, propulsora y propulsada". Certera y espléndidamente despliega el poeta esa bipolaridad, esa tensión del quehacer creador, del discurso poético.

Para el escritor americano "la poesía es un oficio" (1978: 349). Él lo ha ejercido "con amor indeleble" durante muchos años. Él habita en la espontaneidad, pero orientada y dirigida, en anchos mares él gobierna su barco. Él ha asumido la pletórica e inmensa variedad del mundo y de la vida. "Soy omnívoro de sentimientos, de seres, de libros, de acontecimientos y batallas" (1978: 375). Su oficio tiene en la lengua española su instalación primera. Ella es amplia, intensa, abundante, con la fuerza de un poder originario. "El idioma español se hizo dorado después de Cervantes, adquirió una elegancia cortesana, perdió la fuerza salvaje, que traía de Gonzalo de Berceo, del Arcipreste, perdió la pasión genital que aún ardía en Quevedo" (1978: 362). Aquella "belleza congelada" de Góngora no podía decir propiamente el inmenso e indomable mundo de América. Él quiere recuperar el manantial anterior de la lengua española. Él quiere su poesía como hija de una tendencia a lo ilimitado, a la ruptura de fronteras, a la inmensidad. "Yo tenía que ser yo mismo, esforzándome por extenderme como las propias tierras en donde me tocó nacer" (1978: 366). El escritor chileno no quiere ser un escritor desventurado, crucificado, postrado y triste. No quiere ser hijo del "crepúsculo del capitalismo" (1978: 363). Quiere ser el cantor de lo positivo, de la alegría, del progreso y de la transformación de los pueblos. En su fecundo y duradero oficio se le aparecen compañeros orfebres de la palabra, de viejo inmemorable tiempo. Se le aparece Jorge Manrique, "solitario trovador... el buen caballero de la muerte": él habla desde el "tiempo oscuro", con sus manos y su rostro de trigo, desde estructuras de hierro y sombras de diamantes, desde las torres de España. Se le aparece Federico García Lorca, "voz de naranjo enlutado", con su poesía a gritos, como negro relámpago perpetuado, desde "los nidos de aguas doradas" que en él confluyen. Se le aparece Paul Eluard como su amigo y correligionario: su nombre es el de la transparencia y su poesía de cristal. También Pierre Reverdy, quien nombra la evidencia y el esplendor del mundo. Igualmente, el "desgarrador amigo" Rimbaud, con sus ojos penetrantes sobre las sombras, habitante de la desierta soledad. Él ama también la voz de Salvatore Quasimodo, quien transforma la realidad en lenguaje e impregna todo discurso de belleza. Pero sobre todo le acompañan los vivísimos poetas de América: Vallejo, el misterioso creador y morador de la claridad poética; Walt Whitman, con su silueta de bardo, quien le ha enseñado a ser americano. También sus compatriotas: Gabriela Mistral, cuya frente besa y cuya poesía reverencia. Incluso Vicente Huidobro, a quien él llama "poeta de cristal", cuya obra está transcendida de diafanidad.

El gran chileno se piensa y se siente al interno de una honda y secreta corriente de los creadores, de los poetas y profetas de la palabra. Él entona su admiración por la 
casta. Él vive a la sombra prolongada de la historia creada e imaginada por la intensa palabra. Él tiene su imaginario propio del "viejo poeta". Guarda Neruda en lo más hondo de su ánimo la imagen, leyenda y tradición proteica del "viejo poeta". Él es como árbol viejo, en su rostro queda la seca escritura del tiempo. De él permanece "la extendida soledad de su alma", "en sus mejillas todo el misterio". Metido en su traje grande, por los parques sombríos avanza presuroso hacia la muerte.

\section{En el taller nerudiano. Aspectos metodológicos}

Las cosas todas, los elementos todos de la tierra hablarían con la voz de los poetas: "dijeran su lamento / o su silencio / con vuestra voz". Ellos vienen de la íntima región popular, en el "antiguo corazón del pueblo", de sus raíces. Ellos, aunque de voz humilde y sencilla, llevan "la fertilidad y el canto" por doquier. Ellos encarnan el don de aunar pueblo y poesía, ancestral y antiquísimo prodigio. Los vates de "ojos ciegos" -el vate de los vates, Homero- cantaron con su arcaica lira los días de la hermosura y luz de abril, siempre el amor, "el primer beso", también la guerra y los humildes quehaceres de pastores y campesinos como aquel mantuano Virgilio. Pero es Homero el paradigma y modelo de este nobilísimo destino: sabios maestros del verso popular, que componen "con la verdad del pueblo / la eternidad del canto". Ellos trajeron luz a la vida, gozoso anuncio al paso de los días, en la fe sostenida y tenaz de que "la vida / no será siempre triste". Los poetas, "humildemente altivos", entonan la amplia metáfora de la guerra y la paz, de la noche y el alba. Tejedores de sueños, depositarios del "epos" creador y duradero, del lírico carmen, del canto salvador, cálido y comunitario, contra el "tiempo devorador", contra la "huida del irreparable tiempo". Ellos son la melodía dulcísima, la encendida memoria. Habitantes de la palabra, moradores en el bosque de los signos, labran la lengua como canteros de mano cierta sobre los mármoles. En este caso, sobre la lengua castellana, "el cristal de Castilla", riquísimo tesoro para el creador Neruda. Ellos, "mano solidaria", ellos, "palabra / repetida en el canto / y transmitida". Libadores del cántico, "la voz de piedra y agua", señores del origen, de la prístina voz, libérrima y alumbradora, "rapsodia del viento". Y aquel Vallejo, de "crepúsculo negro" en sus ojos, "desterrado del Perú", "ausente de tu arcilla", llegará a ser el centro de su patria, "insurrecto / viviente, I rayo de piedra púrpura". Así dice, vibrante y máximo, el poeta chileno del legendario peruano en "Oda a César Vallejo".

El poeta arde en poesía, pero no se consume. Durante cincuenta años camina con ella. Al principio se sintiera - "me enredabas los pies" - tímido, incierto, confundido y perdido. Años más tarde es poseído por ella - "te ceñiste a mí con los dos brazos de la amante"-. Poseído poéticamente, como copa rebosante. La inspiración, la mirada poética al mundo, la palabra poética, viene a ser lluvia benéfica sobre el secarral, como gota de agua sobre el fuego. Como vida, como crecimiento, como resurrección. Octavio Paz también la quería así en su El arco y la lira: "la poesía es conocimiento, salvación, aban- 
dono... En sus senos se resuelven todos los conflictos objetivos y el hombre adquiere al fin conciencia de ser algo más que tránsito" (Uña 2007). Mas la vida poética profiere la palabra de la cotidianidad, de los humildes quehaceres, de la profundidad de las gentes, de la historia, de la vida misma, de la biografía general sombría, de los sueños y ensueños de los hombres. Hasta hablar "con voz férrea", hasta hacerse sus manos "duras como piedras". El poeta sobrepasa los establecidos respetos y las rígidas convenciones del lírico discurso y compromete su grave metáfora con la opresión, el abandono, la lágrima y la honda pena, también con la reivindicación, con la utopía, con la lucha y el combate. Ella se tornó así voz redentora y convocó a multitudes en la plaza. El poeta se transmuta en alta y amplísima voz, en púlpito, cátedra y oráculo. "Y no dormimos en los caminos", dice. Como los poetas comprometidos, como el anuncio debelador y transformador del mundo. Palabra creadora como aquella proteica palabra del Génesis, que, al nombrar, hace surgir airosamente el mundo. La poesía se torna mismidad, pertenencia, intimidad -"tú, Poesía"-, permanente y amada compañía del poeta: esposa, hermana, madre, novia, "ola marina", "granero inextinguible". Ella es la benéfica guía por los variados círculos del infierno del mundo. Ella es la sugerencia, el sorprendimiento, la creación pura desde el compromiso con el hombre.

Este es el gran Neruda, poeta-río, confundido con el abismo de la naturaleza y de la historia, inmenso, combativo, crepusculario y extravagario, quien levanta la palabra, la vieja palabra castellana, hasta la región de los cóndores, hasta los cielos de los Andes.

"En las Odas elementales me propuse un basamento originario, hacedor. Quise redescribir muchas cosas ya cantadas, dichas y redichas. Mi punto de partida deliberado debía ser el del niño que emprende, chupándose el lápiz, una composición obligatoria sobre el sol, el pizarrón, el reloj o la familia humana. Ningún tema podía quedar fuera de mi órbita; todo debía tocarlo yo andando o volando, sometiendo mi expresión a la máxima transparencia y virginidad" (Neruda 1978: 403-404).

Así habla nuestro autor de sus preciosas odas. Consigue aquí Neruda un elaborado ejercicio de depuración, de limpidez, de ajustamiento. Un extraordinario empeño el suyo al tratar las materias esenciales desde una visión pura y desde una elevada contemplación. Un Neruda torrencial e íntimo, originario y proyectando su yo en mil alumbramientos líricos. "En los tres libros de Odas elementales... hallamos admirables cánticos transparentes a los más variados objetos del mundo, desde el caldillo de congrio al diccionario" (Riquer y Valverde 2005: 826-827). El poeta, que en el Canto general hablaba de "territoriales existencias", "sonoras maderas", "sol sacerdotal", "oro iracundo" y que acumulaba atribuciones propias e impropias a las criaturas variadas (decía también del hombre: "tierra fue, vasija, párpado / del barro trémulo, forma de la arcilla..."), convoca en las Odas elementales una inmensa población de objetos, bajo las más creativas calificaciones. A este amplio rebaño de las cosas, polimorfo y polícromo, advienen variadas contradicciones: son objetos cotidianos, humildes, receptaculares del sufrido uso elemental, pero a su vez son elevados a los gustos y usos refinados del poeta, son parisinos más que arcádicos, más uránicos que de las mansiones de Títiro o Menalcas (dulcia linquimus arva), más de la mano de un selecto dios o egregio héroe 
que de las humildes topografías sicilianas. Doméstico y telúrico, marino y vegetal, al son y claridades del día, así entrega sus intensidades vividas, sus intuiciones agilísimas, sus secretos deseos. Los objetos van marcados por su significativa mansión, secretal, íntima, activísima. Como el acero al rojo vivo, dúctil a toda conformación, tórnase espada o lanza tan concreta y mortal, hiriente ante los ojos. El objeto es sostenido y permanente, se afianza. Se aleja y regresa. Torna y retorna ("torna a cobrar el tino..."). Un proceso creador, ondulado, como ancho mar, secuencial, encadenado, inexorable. Objetos elementales, que se extienden y se exprimen en amplio beneficio, como limón sazonado. De manera tal que la madera parece un bosque, el ajo un vergel, y el pan un campo candeal: una inmensidad de bien iluminada, benéfica y gozosa. Él hablaba de "el cristal de Castilla", como de un tesoro del poeta: quizá la alta luz guilleniana, el don que viene del cielo, que quería Claudio Rodríguez, o quizá la "antigua voz de la tierra", de León Felipe.

Las Odas tienen su antecedente en el Canto general y Las uvas y el viento (las olivas son "pezón del día azul", "reconcentrada terrenal esencia"). El poeta chileno se adentra decididamente en esa tradición fecunda de la poesía que tiene su epicentro de excelencias en la oda, desde Píndaro y los variados excelsos poetas griegos, desde Horacio a Góngora, Fray Luis de León, Whitman, hasta Lorca y las "odas castas" y las "odas libres" de Juan Ramón Jiménez. Nacida como canto, grito lírico, carmen, de las entrañas mismas de la música, de la música coral griega (aquel nietzscheano "espíritu de la música", alumbramiento de las artes de la palabra). Desde la estructura clásica -invocación lírica, declaración de propósito, desarrollo temático y conclusión-, aunque la oda es dada a un cierto anarquismo y a un "hermoso desorden", Neruda suele abundar en una alabanza ágil y concentrada, en una descripción tranquila y en una acumulación descriptiva e inventarial. En la oda, marcada por una notoria ascesis verbal, un lenguaje preciso, ajustado y exacto, el tono fue elevado y solemne. También festivo y entregado a la personalidad y subjetividad creadora del poeta. Los temas que alberga la oda son muy variados: desde los más graves -el poder, los dioses...- a los más concretos, inmediatos y cotidianos (Garrido Gallardo 2009). También tiene su obligado lugar el temario de lo originario, lo nativo, la historia y el patrimonio común: el viejo reino de la identidad. Si el propósito de estos versos nerudianos es decir hermosamente las realidades desde la transparencia y la virginidad, como el poeta confiesa, habrá que añadir otra virtud al ejercicio poético: la ductilidad. Cerca de un centenar de objetos son invocados estéticamente, raptados desde su mortal sueño cotidiano para ser insertos de nuevo en su trama estructural y vital. La universalidad y la particularidad, la totalidad y la singularidad es el segundo juego magistral del poeta. Como si fueran "los trabajos y los días", como si "ab origine mundi", como si "ab urbe condita", como si "de rerum natura" se tratase el asunto: enciclopédica, compendiosamente. "Las Odas elementales sistematizan la ambición nerudiana de hacer un inventario poético del mundo. En ellas se codean objetos, animales, vegetales, seres queridos y detestados, reflexiones morales y conceptos y países y ciudades. Ningún elemento de la realidad escapa, en principio, a la pluma del poeta" (Sicard 2010: 38). Mas los objetos aparecen como muy graves sujetos. Los objetos en su identidad, con su nombre y su signo, en su singularidad, en 
su perfil estricto, en su autenticidad: "Otro de los prodigios realizados por esta poesía de celebración es que el gesto de abarcar se presenta en ella exento de toda confusión. Hay como un neoclasicismo de las Odas elementales, donde el arabesco dibujado en torno al objeto al mismo tiempo lo aísla en un espacio de veneración y lo ata a la infinita multiplicidad" (Ibíd.). La profundidad poética del mundo, el universo de los signos, a la vez que la singularidad expresiva, la concreción del significado. Hermosísimo discurso sobre la identidad y la diferencia. Si el Canto general, con más de quince mil versos, venía a identificarse moral y geográficamente con América (Santí 2009: 14), las Odas elementales se quieren como un himno a la creación. El autor celebra la "faz de la tierra", pero sobrepasando de continuo el establecimiento nomológico de la realidad. Refiriendo la totalidad a la singularidad, la identidad a la diferencia, y viceversa. El canto, en su festivo rito de la pleamar de los signos, rompe lo dado y lo sobrepasa. Crea aquí, como un dios babilónico desde el barro, con su verbo y metáfora un cosmos, una tupida constelación simbólica. El poeta dialoga con el mundo, lo trae hasta su casa, lo invita a cenar, lo hace cercano y hasta íntimo, como objeto de la dulce compañía y del cálido uso y oficio. Es que los objetos miran y caminan decidida e inexorablemente hacia el hombre: él es su centro. Es antropocéntrico este poético ejercicio. El hombre en el vértice de las cosas: ellas elevan su secretal plegaria a las sienes mayestáticas y dulces del hombre. "En el centro de la interminable galaxia resplandece el hombre. Todo hacia él converge" (Sicard 2010: XXXIX).

Por este nerudiano taller desfilan los maestros que hicieron hablar hermosamente al mundo, desde Hesiodo a Aleixandre: los cronistas, notarios, desveladores e imagineros de las "criaturas del alba". Como Virgilio hacía brillar el gozo bienaventurado, las sedes beatas, en la luz ("Largior hic campos aether et lumine vestit / purpureo"), así Neruda dibuja un mundo sustentado en la transparencia y en la diafanidad. Pertenece Neruda por propios poderes a aquella familia de los poetas de la luz y del canto cenital -Petrarca, Garcilaso, Fray Luis de León, San Juan de la Cruz, Guillén, Aleixandre, Claudio Rodríguez...-, que entonaron las criaturas gozosas de los "levantes de la aurora". Aquellos poetas empeñados en remitir el débil e inconsistente mundo a la "región de transparencia". Como si la mansión fuera el mismísimo reino de la luz (la "Oda al aire" hace del mundo materia rigurosa de lo diáfano).

\section{Algunas APORTACIONES Y MíNIMAS CONCLUSIONES}

1) Estas odas, más horacianas que pindáricas, como hemos señalado, tienen especial predilección por las "elementales" criaturas, cercanísimo y cálido mundo: "lo usual, lo circundante o lo genérico, lo inmediato, lo mediato, o lo magno" (Yurkievich 2005: 70). Los críticos y técnicos quieren ver a Neruda aquí como a un fotógrafo de lo cotidiano, como a un cronista de la experiencia común, instalado en la transparencia, en el optimismo constructivo, como niño que juega con el rugiente león del mundo. Y por ello quieren ver 
al autor de estos cantos no como al gran poeta épico sino como a un Virgilio que canta los bucólicos y geórgicos quehaceres ("Nobis placeant ante omnia silvae"), no solo a los "duces". Un Neruda que reincorpora aquí sus vivencias y creencias de la tierra natal, de sus días de niño o quizá un Neruda gozoso en el amor de su amada. Hasta concluir que la grave y torrencial producción del chileno a este respecto es "poesía de lavandería, panadería, tejeduría, metalurgia manchada de aserrín, poesía al paso de los hombres, poesía modesta y firme, simple y directa..." (p. 71).

Todo un tratado de teoría del conocimiento y de semiología discurre en la obra poética del chileno, pero especialmente en sus odas. Población especialísima del signo y la metáfora, mundo como revelación de la hermosura. Objetos como demarcaciones de nuestras proyecciones, como constructos de nuestro no culminado deseo, como estancias de lo vivo soñado. Quizá como reinos y taifas de los variados anhelos, como utopemas cálidos. Arte suprema de fingimiento —como quería Pessoa—, de atribución impropia, de imposición a la realidad de lo inescrutable de nuestro discurso. Signar, nombrar, imponer al mundo nuestros íntimos y desconocidos designios. La construcción objetiva de lo subjetivo, la formalización de lo informe: como un mistérico bautismo. Mas Neruda engarza este oficio de dialogar con el ancho y variopinto mundo desde una instalación en lo gratuito, en la cercanía, en la dulzura y ternura sustentadoras. Los objetos habitan en la proxémica suave y benéfica, son pacíficos y propicios. Con la mansedumbre y dulzura de Virgilio, para quien "las cosas lloran" ("Sunt lacrimae rerum et mentem mortalia tangunt"). "En las Odas... se trata de una relación de yo a tú entre el poeta y los objetos que... pertenecen a un universo ya pacificado, en equilibrio y armonía como para sostener un diálogo tierno, a veces travieso y juguetón, con la figura que los convoca" (Concha 1997: 19).

2) Se nos antoja destacar el interés a este respecto de la "Oda al diccionario". Se narra aquí una historia, como personal, juvenil, a propósito del diccionario, "libro espeso", "con su chaquetón / de pellejo gastado", como un objeto sin mayor sugerencia, significación, gracia o virtualidad, "inútil y anacrónico". Pero un día, por extraña revelación, apareció como una plétora de signos profundos, benéficos, riquísimos, como bosque que avanza, dice y nombra el mundo por sus cuatro costados.

Las palabras, luz intensa, brillaban "fecundas en la fronda del lenguaje / cargadas de verdad y de sonido". Palabras que, al ser pronunciadas, salen de sus bodegas, estallan a la luz, "viven otra vez y dan vida". Las quema el fuego del corazón como teas que en la noche alumbran, marcan caminos, y destinalmente nombran. "Caminos del bosque", al decir de Heidegger. No es osario, ni rincón de muertos el diccionario; ni reino de la distancia y el olvido, que nunca arqueología y protocrónica. El es "preservación", "plantación de rubíes", "perpetuidad viviente de la esencia", "granero del idioma". Como "casa del ser", que quería también Heidegger, hogar y vivísima memoria. Allí habita, dorada por el tiempo, dicha y amada por las generaciones, "la palabra de estirpe", como labrada viva cariátide, "hija de España". En ella es la comunidad, la familia histórica, una inmensa ciudadanía por encima de los espacios y los tiempos. La palabra hispánica, 
"con su hermosura exacta / y su dureza de medalla". Labrada por las intemperies, "extravíos" y "naufragios", por la denodada tarea, por el trágico son de las edades. El poeta mora decidida y vitalmente en esta "profundidad de selva", en estas "mil esmeraldas", en estos "magnánimos graneros", en "antigua madera perfumada". Que el poeta es tierra, pero señor del cántico: "de tierra soy y con palabras canto". Que poéticamente avanza y vive y muere este grandioso hombre de palabra, que en el diccionario alimenta su "trino". Que así el diccionario llega a ser templo de la palabra creadora, dicente, vivísima, como "soledad sonora", que quería el altísimo poeta en su verso; que nunca acumulación invertebrada, cual "tumba, sepulcro, féretro / túmulo, mausoleo", sino urdimbre creadora, musical, al color, en la profundidad del origen como sagrado bosque. Que el poeta hace su pan, su "pan del espíritu", como quería Kafka, de este "granero del idioma", ánfora y quintaesencia de arcaicos y legendarios perfumes. Que vida es la palabra. Que de cercanía y amor fueran los recintos del verbo. Que el diccionario es mucho más que museo y desván, más que un almacén o relicario, más que el lugar de la fijación y acumulación del viaje histórico de los términos. Es la más íntima biografía, la crónica, los "anales" y "centurias" de la comunidad discursiva. Es la herencia de la identidad contra la distancia y el olvido. Es aquel "arte de la memoria" creadora, la central estación de transmisión de las construcciones y reconstrucciones de la expresión y nominación de las realidades. Alli se concita la naturaleza originante y originaria de la comunidad, del "homo loquens".

Juan Páez de Castro, cronista de Carlos V, exhortaba a su señor Felipe II a "fazer insigne librería", donde reposara el conocimiento de los siglos y que Montano disciplinó en provisorios catálogos. El diccionario es la biblioteca por antonomasia, la taxonomía primera del discurso, el domicilio del conocimiento expresado: los términos, las voces, el registro de los nombres y el bautismo de las realidades del mundo. El poeta Neruda ama los libros. En la "Oda al libro, I" y en la "Oda al libro, II" dialoga con el libro: habla y escucha. Lee, recita, escribe y acumula el amplio e intenso libro de la vida: "he aprendido la vida / de la vida". El libro es para él "mínimo bosque", "lámpara clandestina". De la vida al libro y del libro a la vida en continua y creadora peregrinación: "el hombre regresando con un libro".

3) Igualmente se nos antojan como pieza única sus odas a los pájaros. En la "Oda a mirar pájaros" y en la "Oda al pájaro sofré" canta la viviente alada hermosura, el vuelo esplendoroso de las criaturas y sus ascensiones a los cielos, a lo alto, al modo de Fray Luis de León y San Juan de la Cruz. Aquel vuelo virgiliano de las aves a los primeros fríos de otoño ("Quam multae glomerantur aves..."), el "vuelo de la celebración" de Claudio Rodríguez, festividad agilísima, vivaz, espontánea del mundo, de las criaturas aladas, ya celestes. Como una gloria de lo alto este vuelo en la armonía y el cántico. Es el loor de las criaturas, de las "criaturas del alba", anunciadoras, expresantes, simbólicas. Atadas al grito, al pío armonioso, a las misteriosas circulaciones del ritmo. Es el guilleniano "clamor", el "cántico", el "maremágnum" del aire, "aire nuestro", hondamente humano, repoblado de buenas nuevas y de luz pascual. Vuelo y canto salvadores de lo humano ("Todo lo que perdí / volverá con las aves", decía Guillén), culmen azul y celestial del reino de los hombres, tan frágil y tan triste. Estas criaturas tienen todas su 
nombre, su hermoso nombre. Albergan su santo y seña, su tarea y su oficio. Nombres hermosos de la población del aire (diuca, queltehue, huilque, cajamar, chirigüe, chincol, tenca....) Aves de Chile, únicas. Aves que marcan la alta región del día y las oceánicas cinturas de Chile. Como aves del paraíso perdido. Como aves del futuro celestial reino. Retornos de la luz y la vida. Caminos, rutas de los astros. Anuncios del destino. Ellas pueblan "la soledad del aire y su medida". Ellas, "aves de la dulzura", vuelan "el vuelo de la vida", "navegantes del viento". Como los cisnes de Rubén Darío, como las golondrinas de Bécquer. Aquellas aves que, con ojos desmedidamente abiertos, viera Aleixandre: "nacían cada mañana los pájaros, / sorprendentes, novísimos, vividores, celestes". Sus juegos de enigma sobre los campos y el océano, sobre las inmensas cumbres andinas plasman la región de la bienandanza y la buenaventura, la cartografía de la dicha excelsa. Es su mensaje del "día séptimo", de cumplimiento y plenitud de la vida peregrina, dulce estación final del humano viaje. Ellas son vuelo y música: "músicos migratorios", "conversación sagrada", "celeste susurro". Como viviente hermosura o paraíso o plenitud del tiempo.

El poeta Neruda sublima sus creencias: esas aves perdidas en el azul, "ave purísima" como el pájaro sofré, en sus círculos de misterio, son señalados habitantes de la patria, son la "unidad del territorio" y en sus incansables vuelos consiguen reunir "las estrellas de la patria". Ellas son Chile. Las agrestes tierras, el inmenso mar, las poderosas latitudes de las cordilleras son reunidas y abrazadas por este vuelo y este canto desde siempre, ejercicio incansable e insomne. Tal el designio comunitario, perpetuador y salvador del vuelo y canto de las aves. Tal el milagro de la viviente hermosura. "Canto es existencia" (Gadamer 2001: 235). Arte de pájaros (1962-1965) culminará este hermoso tratado de las aves. "Pájaro a pájaro conocí la tierra", dice el poeta de sus peregrinaciones.

4) Dejamos para otra ocasión la descripción y análisis detenidos de las odas al fuego, al aire, a la noche..., cargadas de sugerencias y de riquísimo contenido. Pretendemos establecer una hermenéutica sobre el temario del fuego, especialmente desde las intuiciones de Bachelard, sobre el amplio temario de la luz (del "alma región luciente" de fray Luis de León a la "sombra del paraíso" de Aleixandre) y el aire (de Petrarca a Guillén). También sobre el siempre profundo y vigente temario de la noche (San Juan de la Cruz, Hölderlin, Novalis, Nietzsche, Jaspers, Arendt). "Objetos" altamente significativos, en las más labradas tradiciones expresivas.

5) Hernán Loyola señala que ya en Residencia en la tierra (Neruda 1997: 65-80, 257265) aparecen poemas sobre objetos "elementales" ("Entrada a la madera"; "Apogeo del apio"; "Estatuto del vino"). Allí se dice con certera penetración descriptiva y creativa: "[...] Soy yo con mis lamentos sin origen, sin alimentos, desvelado, solo entrando oscurecidos corredores, llegando a su materia misteriosa". Hasta convertirse en sus ya señalados libros de odas -incluidos Canto general y Las uvas y el viento -, en un maestro genial de la concreción material de lo inmaterial y de la particularización de lo general. La fantasía emocionada del telúrico y oceánico Neftalí Reyes llega a su más elaborada 
metodología en "la objetivación de lo subjetivo", en palabras de un grave analista de los procesos de construcción simbólica y de las estructuras de los símbolos en la poética y semiótica nerudianas (Amado Alonso 1997: 45).

6) El poeta, según este estudioso, elabora una "nomenclatura simbólica particular", que así suena: "[...] rosas y rosales, palomas, mariposas, abejas, hormigas, peces, sal, hombre, campanas, amapolas, uva, piedras, tierra, lana, vino, fuego, trigo, pan, marfil, queso, espadas, pelos, medias". Unos elementos dicen del brillo de la vida y del amor, otros se refieren a la realidad más humilde e insignificante, otros se orientan al mundo del deseo y el anhelo. No obstante, concluye Amado Alonso, "los símbolos de lo elemental y puro son las piedras, la tierra, la lana, el vino, el fuego, el trigo, el pan, el marfil, el cuero, las espadas" (1997: 269). Este retablo sígnico, piensa Loyola, es un "inventario del mundo personal del hablante". Riquísimo, acumulado retablo en el que "desfilan... objetos, utensilios, flores, árboles, animales, alimentos, personajes, símbolos y figuras de su mitología privada... una experiencia acumulada por el yo a lo largo de sus edades míticas personales" (Neruda 1998: I, 220).

7) Para este gran conocedor de la genealogía de la obra del chileno, así como antólogo de la misma, las Odas están transidas de sencillez, tienen un destinatario, "el hombre sencillo", son una "enciclopedia poética popular" (Neruda 1998: I, 220). Sostiene igualmente que su autor fue marcado por los escritos de Rilke y Loti hasta llegar a "modificar su relación con el lenguaje y con los objetos" (1997: 19).

La riqueza expresiva, la capacidad nominativa, los mil sorprendimientos de las realidades, que adelgazan su condición cósica para alimentar torrentes de simbología, vienen a constituir una aportación muy valiosa, singular y acumulada a las circulaciones de significación, o las nunca fijadas relaciones emisor-receptor.

8) La referencia y la traslación -la "usurpata traslatio" agustiniana, característica de la metáfora - tienen en él su abundamiento y sorprendimiento creador únicos. Objetos como universos cargados de significación, de sentido, de valor, de emociones, de afectos. Los entornos cálidos del ser "situado" que es el hombre, los objetos personales, los objetos domésticos, los objetos del oficio, los objetos de la historia, los objetos de la cultura, los objetos del anhelo, los objetos del dilatado reino de la utopía, los objetos de los mundos nunca fijados de la fantasía, de la intuición - que es forma de conocimiento directo, inmediato y total-, de la palabra creadora y dialógica.

Amado Alonso, en su lúcida consideración sobre las relaciones entre conocimiento y sentimiento, entre intelección e intuición, dice pertenecer la poesía nerudiana a una corriente creadora y modo literario de hacer en la que el equilibrio entre "sentimiento, razón y mundo de los objetos se rompe", debido a la prevalencia del sentimiento y la fantasía.

9) Poetas que crean -cita Alonso explícitamente a Aleixandre - torrencialmente, sobrepasando la realidad, desde el sentimiento anegador, con imágenes fragmenta- 
rias, con acumulación de "mil objetos inesperados, heterogéneos: una rueda parada, una mano laxa, un animal dormido, la vista indiferente de una tormenta, un buche, una columnata, un vulgar utensilio diario, iqué sé yo! Objetos desde el seno del sentimiento van emergiendo a la conciencia como instantáneas burbujas" (1997: 92-93).

En verdad, el autor de Parral, llevado a los dos años a la "ciudad maderera" de Tamuco, el cantor de la "madera materna" va a abundar en una incomparable riqueza expresiva para nombrar la "diferencia" de lo real, para dotar de mensaje y sentido a través de las palabras a los mansos objetos de la cercanía, de uso y la costumbre, de la seducción, del "mundo a la mano", de la cotidianidad.

10) El poeta arrancará la voz, el nombre, el signo al mostrenco y asígnico "ser en el mundo" y "ser en el tiempo" para salvarlo en la amplia morada de la expresividad pletórica. Así el gran Neruda puebla los espacios del día habitable, el mar, la luz, el aire, los montes, el cielo y mil habitaciones de lo recóndito de relampagueantes cargas de significación, valor, emoción, afecto, acción, comunicación, sentido y destino.

La condición de creador proteico y magmático de nuestro poeta dice de una instalación en el bosque, como protoplasma y urdimbre de la "edificación del mundo", aquellas "sendas del bosque" heideggerianas preñadas de mil posibilidades hermenéuticas. Él lo confiesa en un hermoso poema, "Primer viaje" de Memorial de Isla Negra: "Las tablas de la casa / olían a bosque / a selva pura. / Desde entonces mi amor / fue maderero / y lo que toco se convierte en bosque. / Que me confunde los ojos y las hojas, / ciertas mujeres con la primavera / del avellano, el hombre con el árbol / como el mundo del viento y del follaje / me distingo entre labios y raíces".

11) Saúl Yurkievich, excelente intérprete de la poesía del chileno, describe así este nacimiento del tupido universo simbólico del joven Neftalí Reyes, "el río invisible" —título de un poemario de 1980 - de su capacidad nominativa y metafórica de la realidad: "Esta comunicación entre hombre y naturaleza, esta confusión de identidades constituye una clave interpretativa. Ese infantil contacto y contagio de Neruda con la lluvia, el viento y el bosque de la Araucanía es su primera experiencia consciente... Portentosa y violenta, esta geografía conglomera, como la poesía nerudiana, selva, montaña y mar, vegetaciones invasoras, humedad de nacimiento y de putrefacción, maderería erguida, tumbada, enternada, aguaceros, borrascas catastróficas. La naturaleza opuesta del sur se fija en la imaginación del poeta hasta construir su basamento primordial, la alimentadora y modeladora de sus visiones" (Neruda 2005: I, 20).

12) En el escritor chileno se cumple como en ningún otro genial creador el oficio de leer y trasladar significativamente el mundo, de vincular poderosa y enigmáticamente el ser y el significar. Así de grave es este arcano y sacerdotal quehacer para los fenomenólogos: "En las creaciones de la fantasía, el objeto, aunque evidentemente no es objeto después de haber sido cosa, implica unas determinadas realidades cuyas imágenes se 
combinan en él de un modo nuevo como materiales ordenados con una nueva configuración" (Millán-Puelles 1990:109).

13) Las palabras poéticas en torno a los objetos elementales, desde Virgilio y Horacio hasta Neruda, vienen a ser un recurso y aportación a la teoría de la comunicación de múltiples posibilidades sin explotar. Ello amplía el discurso filosófico y semiológico, la teoría del lenguaje elaborado y fecunda la investigación fenomenológica de los objetos. Para el excelso creador de Isla Negra la poesía es radicalmente comunicación: "tu paso entre los pasos de los hombres". Ella es la gran compañera, creadora fecunda de la vida, "la palabra / repetida en el canto / y transmitida". Asimismo, el poeta es solidario: él habla por los hombres y las cosas. El poeta Neruda, transido de optimismo, con mirada creadora y gozosa sobre el mundo, instalado en los anuncios matutinos -en el alba, en el origen, en la plenitud, en lo diáfano, en la instantaneidad radiante-, torrencial, palingenésico y mítico, entrega agilísimamente baños de luz y dádivas del aire a los objetos.

\section{REFERENCIAS BibLIOGRÁFICAS}

Adorno, Th. W. 1980. Teoría estética. Madrid: Taurus.

Adorno, Th. W. 2003. Notas sobre literatura, (Obra completa, 11). Madrid: Akal.

(de) Alessi, F. 1991. Heidegger lettore dei poeti. Turín: Rosenberg and Seillier.

Alonso, A. 1997. Poesía y estilo de Pablo Neruda. Madrid: Gredos.

Arias Montano, B. 2009. Tractatus tertius de Fide, quae revelanda erat. Adam, sive de humani sensus interprete lingua. Huelva: Universidad de Huelva.

Bachelard, G. 1939. Lautrémont. París: José Corti.

Bachelard, G. 1966. Psicoanálisis del fuego. Madrid: Alianza.

Bachelard, G .1973. La intuición del instante. Buenos Aires: Siglo Veinte.

Bachelard, G. 1993. La poética de la ensoñación. México: Fondo de Cultura Económica.

Bachelard, G. 1994. La tierra y los ensueños de la voluntad. México. Fondo de Cultura Económica.

Barthes, R. 1971. Elementos de Semiología. Madrid: Alberto Corazón Editor.

Barthes, R. 1990. El imperio de los signos. Madrid: Mondadori.

Barthes, R. 2001. Variaciones sobre la literatura. Barcelona: Paidós.

Barthes, R. 2002. El susurro del lenguaje. Más allá de la palabra y la escritura. Barcelona: Paidós.

Barthes, R. 2003. La aventura semiológica. Barcelona: Paidós.

Barthes, R. 2009. Lo obvio y lo obtuso. Imágenes, gestos y voces. Barcelona: Paidós. 
Baudelaire, Ch. 1988. Curiosidades estéticas. Madrid: Júcar.

Baudrillard, J. 1977. El sistema de los objetos. México: Siglo Veintiuno.

Bell, D. 1994. Las contradicciones culturales del capitalismo. Madrid: Alianza.

Benjamin, W. 1986. Reflections: essays, aphorisms, autobiographical writings. Nueva York: Schocken.

Bloch, E. 1982. Sujeto-objeto: el pensamiento de Hegel. Madrid: Fondo de Cultura Económica.

Bourdieu, P. 1988. La distinción. Criterio y bases sociales del gusto. Madrid: Taurus.

Bourdieu, P. 1995. Las reglas del arte. Génesis y estructura del campo literario. Barcelona: Anagrama.

Bousoño, C. 1996. Teoría de la expresión poética. Madrid: Gredos.

Brink, C. O. 1963. Horace on Poetry I: Prolegomena to the Literary Epistles. Cambridge: University Press Cambridge.

Brunori, G. 1930. La lingua d'Orazio. Florencia: Vallecchi.

Burke, P. 1987. Sociología e historia. Madrid: Alianza.

Cohen, J. 1970. Estructura del lenguaje poético. Madrid: Gredos.

Concha, J. comp.1997. Introducción a Neruda, P., Odas elementales. Madrid: Cátedra.

Corti, M. 1976. Principi della comunicazione letteraria. Milán: Bompiani.

(de) Costa, R. 1979. The Poetry of Pablo Neruda. Cambridge-Mass.: Harvard University Press.

Cuesta Abad, J. M. 1977. Las formas del sentido: estudio de poética y hermenéutica. Madrid: Ed. de la Universidad Autónoma de Madrid.

Cuesta Abad, J. M. 1991. Teoría hermenéutica y literatura (El sujeto del texto). Madrid: Visor.

Daigueperse, M. 1979-1980. Écriture et mythe. Recherches sur la langue poétique de Neruda dans "Residencia en la tierra" (Mémoire de maitrise). Bordeaux: Université de Bordeaux.

Dawes, G. 2010. Poetas ante la Modernidad: Vallejo, Huidobro, Neruda y Paz. Madrid: Fundamentos.

Debicki, A. P. 1976. Poetas hispanoamericanos contemporáneos. Punto de vista, perspectiva, experiencia. Madrid: Gredos.

Derrida, J. 1985. La voz y el fenómeno. Valencia: Pre-Textos.

Derrida, J. 1997. "Adiós". Revista de Occidente 196:5-16.

Derrida, J. 2003. Palabra. Madrid: Trotta.

Descartes, R. 2008. Discurso del método. Meditaciones metafísicas. Madrid: Tecnos.

(van) Dijk, T. A. 1976a. Per una poetica generativa. Bolonia: II Mulino.

(van) Dijk, T. A. 1976b. Pragmatics of Language and Literature. Amsterdam: North-Holland.

Duval, R. 1976. "Parole, expression, silence. Recherches sur le parole comme révélatrice d'autri ". Revue des Sciénces philosophiques et théologiques 60:226-260. 
Eco, U. 1980. Signo. Barcelona: Lumen.

Edwards, J. 2010. "El racionalismo que domina en las Odas elementales". Pp. 13-28 en Antología general, compilada por Hernán Loyola. Madrid: Real Academia Española-Asociación de Academias de la Lengua Española.

Escarpit, R. 1968. Sociología de la literatura. Barcelona: Edima.

Escudero, J. A. 2009. El lenguaje de Heidegger. Diccionario filosófico 1912-1927. Barcelona: Herder.

Etxeberría, M. 2002. La diversidad de lenguas en España. Madrid: Espasa.

Fabris, A. 2001. Giro lingüístico: hermenéutica y análisis del lenguaje. Madrid: Akal.

Ferrater Mora, J. 1970. Indagaciones sobre el lenguaje. Madrid: Alianza.

Ferrater Mora, J. 2005. Diccionario de Filosofía, IV. Barcelona: RBA.

Fonagy, I. 1971. "Communication in Poetry”. Word 17:194-218.

Foucault, M. 1979. Las palabras y las cosas. Madrid: Siglo Veintiuno.

Fraisse, P. y Jean Piaget. 1974. Lenguaje, comunicación y decisión. Buenos Aires: Paidós.

Francalanci, E. L. 2010. Estética de los objetos. Madrid: La balsa de la Medusa.

Furió, V. 2000. Sociología del arte. Madrid: Cátedra.

Gadamer, H. G. 1993. Aesthetik und Poetik, I-II (Gesammelte Werke, vols. VIII y IX). Tubinga: J. C. B. Mohr.

Gadamer, H. G. 1998. Arte y verdad de la palabra. Barcelona: Paidós.

Gadamer, H. G. 1999. Poema y diálogo. Barcelona: Gedisa.

Gadamer, H. G. 2001. ¿Quién soy yo y quién eres tú? Comentario a «Cristal de aliento» de Paul Celan. Barcelona: Herder.

Gallardo, A. 2010. "Pablo Neruda y la lengua castellana". Pp. 599-616 en Antología general, compilada por Hernán Loyola. Madrid: Real Academia Española-Asociación de Academias de la Lengua Española.

Garrido Gallardo, A. 2009. El lenguaje literario. Vocabulario crítico. Madrid: Síntesis.

Gimferrer, P. 2009. "Reflexiones sobre la palabra poética". Barcarola 73:59-81.

Godelier, M. 1989. Lo ideal y lo material. Madrid: Taurus.

Goldmann, L. 1975. Para una sociología de la literatura. Madrid: Ayuso.

Gombrich, E. H. 1983. L'écologie des images. París: Flammarion.

Gracián, B. 1987. Agudeza y arte de ingenio. Madrid: Castalia.

Gramsci, A. 1973. Cultura y literatura. Barcelona: Península.

Greimas, J. A. 1976. Lingüistica y comunicación. Buenos Aires: Nueva Visión.

Guyau, J. M. 1931. El arte desde el punto de vista sociológico. Madrid: Daniel Jorro. 
Hartmann, N. 1957. Rasgos fundamentales de una metafísica del conocimiento. Buenos Aires: Losada. Hartmann, N. 1976. Metafísica del conocimiento y de la acción. Caracas: Fondo de Cultura Económica. Hauser, A. 2005. Historia social de la literatura y el arte I-II. Barcelona: RBA.

Hegel, G. W. F. 1983. Estética. Buenos Aires: Siglo Veinte.

Heidegger, M. 1973. Arte y poesía. México: Fondo de Cultura Económica.

Heidegger, M. 1979. Sendas perdidas. Buenos Aires: Losada.

Heidegger, M. 1987. De camino al habla. Barcelona: Serbal.

Heidegger, M. 1989. Hölderlin y la esencia de la poesía. Barcelona: Anthropos.

Heidegger, M. 1995. Caminos del bosque. Madrid: Alianza.

Heidegger, M. 2005. Aclaraciones a la poesía de Hölderlin. Madrid: Alianza.

Heidegger, M. 2009. El arte y el espacio. Barcelona: Herder.

Heidegger, M. 2010. Pensamientos poéticos. Barcelona: Herder.

Horacio. 2008. Odas, Epodos. Madrid-Barcelona: RBA-Gredos.

Horster, D. 1979. Die Subjekt-Objekt-Beziehung im Deutschen Idealismus und in der Marxchen Philosophie. Francfort: Campus.

Huidobro, V. 1996. Poesía y poética (1911-1948). Madrid: Alianza.

Husserl, E. 1929. Investigaciones lógicas. Madrid: Revista de Occidente.

Husserl, E. 2006. Meditaciones cartesianas. Madrid: Tecnos.

Jakobson, R. 1960. "Linguistics and Poetics". Pp. 350-377 in Style in Language, editado por T. Sebeok. Cambridge (Mass.): MIT Press.

Jauss, H. R. 1982. Äesthetische Erfahrung und literarische Hermeneutik. Francfort: Suhrkamp.

Kaehler, K. E. 2010. Das Prinzip Subjekt und seine Krisen. Múnich: Alber.

Kant, I. 2010. Crítica de la razón pura. Madrid: Gredos.

Kayser, W. 1981. Interpretación y análisis de la obra literaria. Madrid: Gredos.

Lacan, J. 2008. Escritos, I. Madrid: Siglo XXI.

Lévi-Strauss, C. 1965. Tristes tropiques. París: 18 de Octubre.

Levin, S. R. 1987. "Consideraciones sobre qué tipo de acto de habla es un poema". Pp. 59-82 en Pragmática de la comunicación literaria, editado por José Antonio Mayoral. Madrid: Arco Libros.

Levin, S. R . 1974. Estructura lingüística en la poesía. Madrid: Cátedra.

Lizalde, E. 2010. "Neruda, río". Pp. 629-636 en P. Neruda. Antología general, compilada por Hernán Loyola. Madrid: Real Academia Española-Asociación de Academias de la Lengua Española.

Lodares, J. R. 2001. Gente de Cervantes. Historia humana del idioma español. Madrid: Taurus. 
Lotman, I. 1970. Estructura del texto artístico. Madrid: Istmo.

Loyola, H. 2006. Neruda. La biografía literaria, I: 1904-1932. Santiago: Planeta-Seix Barral.

Luckács, G. 1966. Problemas del realismo. México: FCE.

Luckács, G. 1967. Estética. Barcelona: Grijalbo.

Luckács, G. 1969. Prolegómenos a una estética marxista. Barcelona: Grijalbo.

Luckács, G. 1975. El alma y las formas. La teoría de la novela. Barcelona: Grijalbo.

Luckács, G. 1975. Sociología de la literatura. Barcelona: Península.

Luckács, G.1984. Sociología actual del realismo crítico. México: Era.

Lyon, J. K. 2006. Paul Celan and Martin Heidegger: An unresolved conversation, 1951-1970. Baltimore: John Hopkins University Press.

Macías, S. 2004. El Madrid de Pablo Neruda. Madrid: Tabla Rasa Libros y Ediciones.

Martínez Bonat, F. 1983. La estructura de la obra literaria. Barcelona: Ariel.

Martínez García, J. A. 1975. Propiedades del lenguaje poético. Oviedo: Archivium.

Marx, K. 1963. L'idéologie allemande. París: Éditions sociales.

Mayor, J. 1977. Psicología de la comunicación. Madrid: Ed. Universidad Complutense.

McNabb, D. 2009. "Benjamin y el lenguaje: reflexiones desde Charles S. Peirce". Anthropos 225:136-146.

Melnick, A. 2009. Kant's theory of the self. Nueva York: Routledge.

Micó, J. M. 2008. Las razones del poeta. Forma poética e historia literaria de Dante a Borges. Madrid: Gredos.

Michon, P. 2000. Poètique d'une anti-anthropologie: I'hermenéutique de Gadamer. París: J. Vrin.

(de) Miguel, A. 2009. La magia de las palabras. Madrid: Instituto de Formación Avanzada.

Millares, S. 2008. Neruda: el fuego y la fragua. Salamanca: Ediciones de la Universidad de Salamanca.

Millán-Puelles, A. 1990. Teoría del objeto puro. Madrid: Rialp.

Miller, G. 1979. Lenguaje y comunicación. Buenos Aires: Amorrortu.

Moles, A. 1975a. Teoría de la información y percepción estética. Madrid: Júcar.

Moles, A. 1975b. Teoría de los objetos. Barcelona: Gustavo Gili.

Moreno Fernández, F. 2009. Principios de sociolingüística y sociología del lenguaje. Barcelona: Ariel.

Morin, E. 2001. Amor, poesía, sabiduría. Barcelona: Seix Barral.

Morón Arroyo, C. 1998. Las Humanidades en la era tecnológica. Oviedo: Nobel.

Mounin, G. 1969. La communication poètique. París: Gallimard.

Mounin, G. 1970. Introduction á la sémiologie. París: De Minuit. 
Mounin, G. 1975. Linguistique et Philosophie. París: De Minuit.

Neruda, P. 1987. Residencia en la tierra. Madrid: Cátedra.

Neruda, P. 1997. Odas elementales. Madrid: Cátedra.

Neruda, P. 1998. Antología poética, I-II. Madrid: Alianza.

Neruda, P. 2002. Confieso que he vivido. Memorias. Barcelona: Seix Barral.

Neruda, P. 2005-2007. Obras Completas. Barcelona: RBA-Círculo de Lectores.

Neruda, P. 2009. Canto general. Madrid: Cátedra.

Neruda, P. 2010a. Antología general. Madrid: Real Academia Española-Asociación de Academias de la Lengua Española.

Neruda, P. 2010b. Cartas de amor. Cartas a Matilde Urrutia (1950-1973). Barcelona: Seix Barral.

Núñez Ramos, R. 2010. El pensamiento narrativo. Aspectos cognitivos del relato. Oviedo: Universidad de Oviedo.

Onimus, J. 1970. La communication littèraire: culture et savoir. Brujas: De Brouwer.

Oomen, U. 1973. Linguistiche Grundlagen poetische Texte. Tubinga: Niemeyer.

Oomen, U. 1987. "Sobre algunos elementos de la comunicación poética". Pp. 137-149 en Pragmática de la comunicación literaria, editado por J. A. Mayoral. Madrid: Arco Libros.

Pignatari, D. 1977. Información, lenguaje y comunicación. Barcelona: Gustavo Gili.

Pöggeler, O. 1986. Spur des Works. Zur Lyrik Paul Celans. Friburgo-Múnich: Alber.

Popper, K. R. 2001. Conocimiento objetivo. Madrid: Tecnos.

Posner, R. 1982. Rationnal Discourse and Poetic Communication. La Haya: Mouton.

Pozuelo Yvancos, J. M. 2003. Teoría del lenguaje literario. Madrid: Cátedra.

Prieto, A. 1976. Ensayo semiológico de sistemas literarios. Barcelona: Planeta.

Quine, O. 2002. Palabra y objeto. Barcelona: Herder.

Richard, J. P. 1955. Poésie et profondeur. París: Seuil.

Ricoeur, P. 1980. La metáfora viva. Madrid: Cristiandad.

(del) Río, A. 2010. Historia de la Literatura Española. Barcelona: RBA.

Rodríguez Monegal, E. y Enrico Mario Santí. 1986. Pablo Neruda. Madrid: Taurus.

Ruwe, T. M. 1972. Langage, musique, poésie. París: Seuil.

Safranski, R. 2006. Heidegger y el comenzar. Madrid: Círculo de Bellas Artes.

Safranski, R. 2009. Romanticismo. Una odisea del espíritu alemán. Barcelona: Tusquets.

Santí, E. M. 2009. Introducción a Neruda, P., Canto general. Madrid: Cátedra. 
Sartre, J. P. 1984. Baudelaire. Alianza: Madrid.

(de) Saussure, F. 1916. Cours de linguistique génerale. París: Payot.

Schrimp, H. J. 1957. "Hölderlin, Heidegger und die Literaturwissenschaft". Euphorion 51:308-324.

Silbermann, A. 1973. Empirische Kunstsoziologie. Stuttgart: Enke.

Sicard, A. 1981. El pensamiento poético de Pablo Neruda. Madrid: Gredos.

Sicard, A. 2006. "Neruda: la poética de los objetos". Nerudiana 2:8-14.

Sicard, A. 2010. "Pablo Neruda: Entre lo inhabitado y la fraternidad". Pp. 29-53 en Antología general, compilada por Hernán Loyola. Madrid: Real Academia Española-Asociación de Academias de la Lengua Española.

Simmel, G. 2005. Goethe. Buenos Aires: Prometeo.

Sombart, N. 1979. Lujo y capitalismo. Madrid: Alianza.

Steiner, G. 1990. Lenguaje y silencio. Ensayos sobre la literatura, el lenguaje y lo inhumano. Barcelona: Gedisa.

Strassberg, D. 2007. Das poietische Subjekt: Giambattista Vicos Wissenschaft vom Singulären. München: W. Fink.

Suárez, J. L. 2001. Herederos de Proteo. Una historia del Humanismo español. Huelva: Universidad de Huelva.

Suárez de la Torre, F. 2007. Teoría y práctica de la composición poética en el Mundo Antiguo y su pervivencia. Valladolid: Universidad de Valladolid.

Thayer, L. 1975. Comunicación y sistemas de comunicación. Barcelona: Península.

Tiniánov, I. 2010. El problema de la lengua poética. Buenos Aires: Dedalus.

Trabant, J. 1975. Semiología de la obra literaria. Glosemática y teoría de la literatura, Madrid: Gredos.

Uña, O. 1983. La comunicación en Karl Jaspers. Madrid: Universidad Complutense.

Uña, O. 1984a. Comunicación y libertad. S. L. de El Escorial: Ed. Escurialenses.

Uña, O. 1984b. "La comunicación objetiva en Karl Jaspers". Pp. 193-223 en Sobre la violencia y la ética. Homenaje al profesor J. L. L. Aranguren. Madrid: Ed. de la Cruz Roja.

Uña, O. 1987. "Sobre el estatuto epistemológico de la Sociología de la comunicación humana". Cuadernos Salmantinos de Filosofía XIV:201-246.

Uña, O. 1990. "Comunicación y sociedad". Pp. 22-55 en El cambio: libertad de expresión y medios de comunicación social. Santiago de Compostela: Ed. de la Consellería de Presidencia e Administración Pública.

Uña, O. 1998. Teoría sociológica y comunicación. Madrid-Sidney-Auckland: Australasian Hispanic Society.

Uña, O. 1999. "Deducciones desde el yo. Planteamiento del problema de la comunicación en el pensamiento de la modernidad". Praxis Sociológica 4:17-57. 
Uña, O. 2006. Estaciones de abril. Madrid: Dykinson.

Uña, O. 2007. "De conceptos, lenguajes y metáforas: Carlos Moya y Octavio Paz". Pp. 865-885 en Lo que hacen los sociólogos. Homenaje a Carlos Moya. Madrid: CIS.

Uña, O. 2008. "Comunicación y lenguaje poético: El caso de Gadamer". Revista Española de Sociología 9:87-106.

Uña, O. 2009. Nuevos ensayos de sociología y comunicación. Madrid: Universitas.

Valverde, J. M. y Martín de Riquer. 2005. Historia de la Literatura Universal, II. Barcelona: RBA.

Villegas, J. 1976. Estructuras míticas y arquetipos en el "Canto general" de Neruda. Barcelona: Planeta.

Weber, M. 2009. La "objetividad" del conocimiento en la ciencia social y en la política social. Madrid: Alianza.

Yurkievich, S. 2005. "Introducción general". Pp. 11-81 en Obras Completas, I. Barcelona: RBA-Círculo de Lectores.

Zavala, I. M. 2009. La (di)famación de la palabra. Ensayos polémicos de ética y cultura. Barcelona: Anthropos.

Zima, P. V. 2007. Theorie des Subjekts. Subjektivität und Identität zwischen Moderne und Postmoderne. Tubinga: Francke.

Zizek, S. 2010. El sublime objeto de la ideología. Madrid: Siglo XXI.

OCTAVIo UÑa es Doctor y premio extraordinario de doctorado por la Universidad Complutense. Catedrático de filosofía (IES), catedrático de sociología (Universidades de Santiago de Compostela, Complutense, Castilla-La Mancha y Rey Juan Carlos). Profesor en la Escuela Diplomática, en el CESEDEN y en un amplio número de universidades extranjeras. Ha sido decano y director del Real Colegio Universitario María Cristina (U. Complutense) y decano de la Facultad de Humanidades (U. de Castilla-La Mancha). Presidente del Instituto Ciencia y Sociedad y de la Asociación Castellano-Manchega de Sociología, director de Barataria. Autor de una extensa obra de sociología y literaria. Sus líneas de investigación comprenden: la sociología del conocimiento y la comunicación, la sociología de la cultura y la teoría sociológica.

RECIBIDO: $11 / 02 / 2013$

ACEPTADO: 29/08/2013

PUBLICADO ONLINE: 19/05/2014 